\title{
Positive glypican-3 expression in early hepatocellular carcinoma predicts recurrence after hepatectomy
}

\author{
I-Pei Chen · Shun-ichi Ariizumi • Masayuki Nakano • \\ Masakazu Yamamoto
}

Received: 12 November 2012/ Accepted: 7 March 2013/Published online: 27 March 2013

(C) The Author(s) 2013. This article is published with open access at Springerlink.com

\begin{abstract}
Background Glypican-3 (GPC3) is a new prognostic factor after curative hepatectomy in patients with hepatocellular carcinoma (HCC), and the expression of GPC3 is known to be associated with postoperative metastasis. However, the role of GPC3 in patients with early HCC remains unknown.

Methods We retrospectively studied 55 patients with early HCC (total 99 nodules) who underwent initial hepatectomy between 1995 and 2010. Clinicopathological features and surgical outcomes were compared in relation to GPC3 expression.

Results The GPC3-positive expression was seen in 28 of 55 patients $(50.9 \%)$ with early HCC (44 of 99 nodules). The GPC3-positive expression was significantly associated with hepatitis $\mathrm{C}$ virus $(\mathrm{HCV})$ infection $(P=0.0019)$ and with multiple early HCCs $(P<0.0001)$. The 5 -year disease-free survival rate was significantly lower in patients with GPC3-positive early HCC (27\%) than in patients with GPC3-negative early HCC $(62 \%, P=0.0036)$. The GPC3 expression was a significant independent prognostic
\end{abstract}

I.-P. Chen · S. Ariizumi · M. Yamamoto $(\bowtie)$

Department of Surgery, Institute of Gastroenterology,

Tokyo Women's Medical University, 8-1 Kawada-Cho,

Shinjuku-Ku, Tokyo 162-8666, Japan

e-mail: yamamoto@ige.twmu.ac.jp

I.-P. Chen

e-mail: ipchen39@gmail.com

S. Ariizumi

e-mail: ariizumi@ige.twmu.ac.jp

M. Nakano

Department of Pathology, Ofuna Chuo Hospital,

Ofuna, Kamakura, Kanagawa, Japan

e-mail: masayuki-nakano@ofunachuohp.net factor for disease-free survival. However, it showed no significant difference in overall survival.

Conclusions The GPC3 expression is capable to be a new prognostic factor for disease-free survival in patients with early HCC.

Keywords GPC3 - Early hepatocellular carcinoma · Surgical outcome

\section{Introduction}

Hepatocellular carcinoma (HCC) is the fifth most common malignancy and the third most common cause of cancerrelated death worldwide [1]. Infections with hepatitis B virus (HBV) or hepatitis $\mathrm{C}$ virus (HCV), which lead to chronic liver disease and are often associated with cirrhosis, are the major risk factors for HCC.

Glypican-3 (GPC3) is a heparin sulfate proteoglycan involved in migration, proliferation and modulation of cell survival in several tissues [2-6]. Expression of GPC3 has been observed in some embryonic tissues, including liver, but it is silenced in the corresponding normal adult tissue [7]. The GPC3 expression was also found to be higher in $72 \%$ of advanced HCC tissues and was undetectable in normal liver, cirrhotic liver or liver with focal lesions such as dysplastic nodules and areas of hepatic adenoma (HA) $[6,8-11]$. The expression of GPC 3 was also found to relate with postoperative metastasis in advanced HCC patients [12-14].

The role of GPC3 in patients with early HCC is still unclear and it remains to be elucidated. This work was undertaken to determine the role of GPC 3 in early HCC and, additionally, to evaluate its relation to outcomes of patients with early HCC. 


\section{Patients and methods}

Patients

Between 1995 and 2010, 55 consecutive patients with 99 tumors of early HCC who had undergone initial hepatectomy at Tokyo Women's Medical University Hospital were retrospectively selected in the study. All 99 resected tumors were pathologically diagnosed as early HCC. Of these 55 patients, 37 had solitary early HCC and 18 had multiple early HCC (total 62 nodules; range 2-9 nodules/patient; mean $3.5 \pm 1.8$ nodules/patient).

\section{Diagnostic criteria}

According to the classifications of the Liver Cancer Study Group of Japan [15] and the International Consensus Group for Hepatocellular Neoplasia in 2009 [16], the diagnosis of early HCC consisted of: grossly, indistinct tumor margin with size less than $2 \mathrm{~cm}$ in greatest diameter, and upon histologic analysis, the varying combination of the following features: (1) increased cell density, with an increased nuclear/cytoplasmic ratio and irregular thintrabecular pattern; (2) diffuse fatty change; (3) varying numbers of portal tracts within the nodule (intratumoral portal tracts); (4) early HCC cells involving the portal tract, showing invasion by cancer cells with unremarkable cellular atypia, which is a key point of histological differential diagnosis from high-grade dysplastic nodules of the liver. When the early HCC was seen multifocally, the patient was given a diagnosis with multiple early HCCs. Patients with nodule in nodule HCC (advanced HCC within early HCC) were excluded in this study.

Demographic patient characteristics included in the analysis are summarized in Table 1. The study protocol conformed to the ethical guidelines of the World Medical Association Declaration of Helsinki.

\section{Immunohistochemistry}

Immunohistochemical staining for GPC3 and Alfa-fetoprotein (AFP) were performed using formalin-fixed and paraffin-embedded tissue sections. The primary monoclonal antibodies used were anti-GPC3 (clone 1G12, Biomosaics, Burlington, VT) and anti-Alfa-fetoprotein (Dako, Carpinteria, CA). Briefly, 4- $\mu \mathrm{m}$ sections from formalinfixed, paraffin-embedded tissue blocks were deparaffinized in xylene and rehydrated through ethanol to water. Endogenous peroxidase activity was blocked using $3 \%$ $\mathrm{H}_{2} \mathrm{O}_{2}$ in methanol for $15 \mathrm{~min}$. Following heat-induced epitope retrieval in $0.1 \mathrm{~mol} / \mathrm{L}$ of citrate buffer at $\mathrm{pH} 6.0$ in a microwave for $20 \mathrm{~min}$, the slides were incubated overnight at $4{ }^{\circ} \mathrm{C}$ with mouse monoclonal antibody specific for
Table 1 Correlation between GPC3 expression and clinicopathological features of early HCC patients

\begin{tabular}{|c|c|c|c|}
\hline \multirow{2}{*}{$\begin{array}{l}\text { Clinicopathological } \\
\text { features }\end{array}$} & \multicolumn{2}{|c|}{ GPC3 expression } & \multirow[t]{2}{*}{$P$ value } \\
\hline & $\begin{array}{l}\text { Positive } \\
(n=28)\end{array}$ & $\begin{array}{l}\text { Negative } \\
(n=27)\end{array}$ & \\
\hline Age (years, mean $\pm \mathrm{SD})$ & $65.5 \pm 1.4$ & $63.5 \pm 1.4$ & 0.3338 \\
\hline \multicolumn{4}{|l|}{ Gender } \\
\hline Male & 18 & 18 & \multirow[t]{2}{*}{0.7757} \\
\hline Female & 10 & 9 & \\
\hline \multicolumn{4}{|l|}{ HBs antigen } \\
\hline Positive & 1 & 6 & \multirow[t]{2}{*}{0.038} \\
\hline Negative & 27 & 21 & \\
\hline \multicolumn{4}{|l|}{ HCV antibody } \\
\hline Positive & 27 & 17 & \multirow[t]{2}{*}{0.0019} \\
\hline Negative & 1 & 10 & \\
\hline \multicolumn{4}{|l|}{ Cirrhosis } \\
\hline Present & 16 & 18 & \multirow[t]{2}{*}{0.3157} \\
\hline Absent & 12 & 9 & \\
\hline \multicolumn{4}{|l|}{ Child-Pugh grade } \\
\hline Child A & 23 & 24 & \multirow[t]{2}{*}{0.4437} \\
\hline Child B or C & 5 & 3 & \\
\hline $\mathrm{ICG} \mathrm{R}_{15}(\%$, mean $\pm \mathrm{SD})$ & $18.0 \pm 1.5$ & $16.6 \pm 1.5$ & 0.5095 \\
\hline $\mathrm{AFP}(\mathrm{ng} / \mathrm{mL}$, mean $\pm \mathrm{SD})$ & $74.1 \pm 17.7$ & $42.2 \pm 17.7$ & 0.2086 \\
\hline $\begin{array}{l}\text { PIVKA-II }(\mathrm{mAU} / \mathrm{L} \\
\text { mean } \pm \mathrm{SD})\end{array}$ & $22.5 \pm 5.9$ & $14.4 \pm 5.6$ & 0.3422 \\
\hline \multicolumn{4}{|l|}{ Number of early HCC } \\
\hline Solitary & 12 & 25 & \multirow[t]{2}{*}{$<0.0001$} \\
\hline Multiples & 16 & 2 & \\
\hline \multicolumn{4}{|l|}{ Resection procedures } \\
\hline Sectionectomy or larger & 19 & 16 & \multirow[t]{2}{*}{0.5076} \\
\hline Segmentectomy or smaller & 9 & 11 & \\
\hline $\begin{array}{l}\text { Tumor size }(\mathrm{cm}, \\
\text { mean } \pm \mathrm{SD})\end{array}$ & $1.9 \pm 0.2$ & $2.0 \pm 0.2$ & 0.4809 \\
\hline
\end{tabular}

GPC3 Glypican3, HCC hepatocellular carcinoma, HBs antigen hepatitis $\mathrm{B}$ surface, $H C V$ hepatitis $\mathrm{C}$ virus, $I C G R_{15}$ indocyanine green retention rate at $15 \mathrm{~min}, A F P$ alpha-fetoprotein, PIVKA-II protein induced by vitamin $\mathrm{K}$ absence and antagonist-II

GPC3 (clone 1G12, Biomosaics) diluted 1:100 and 1:50 for AFP. After incubation with a rabbit antimouse secondary antibody, a reaction was performed using the Envision Plus detection system that contained biotin-free horseradish peroxidase-labeled polymers (Dako, Carpinteria, CA). The staining was visualized using 3,3'-diaminobenzidine substrate-chromogen solution and counterstained with hematoxylin. For GPC3, cytoplasmic and/or peri-canalicular immunoreactivity were assessed. For AFP, cytoplasmic immunoreactivity was assessed.

Immunohistochemically stained slides were independently evaluated by 2 observers. Cases with significantly discrepant interpretation were resolved by review of the 2 observers together. Staining for GPC3 (cytoplasmic and/or 
Fig. 1 Early HCC and GPC3 expression. a Early HCC with diffuse fatty changes. Portal tract invasion (arrow head) $(\mathrm{H} \& \mathrm{E}, \times 10)$. b Cancer cells invade the stromal of the portal tract (arrow heads) (VBHE, $\times 20$ ). $\mathbf{c}$ Positive expression of GPC3 in cancerous areas but negative in non-cancerous areas $(\times 10)$. d Higher magnification shows a GPC3-positive pericanalicular pattern and invasion of GPC3-positive cancer cells to the stromal of the portal tract (arrow heads) $(\times 20)$
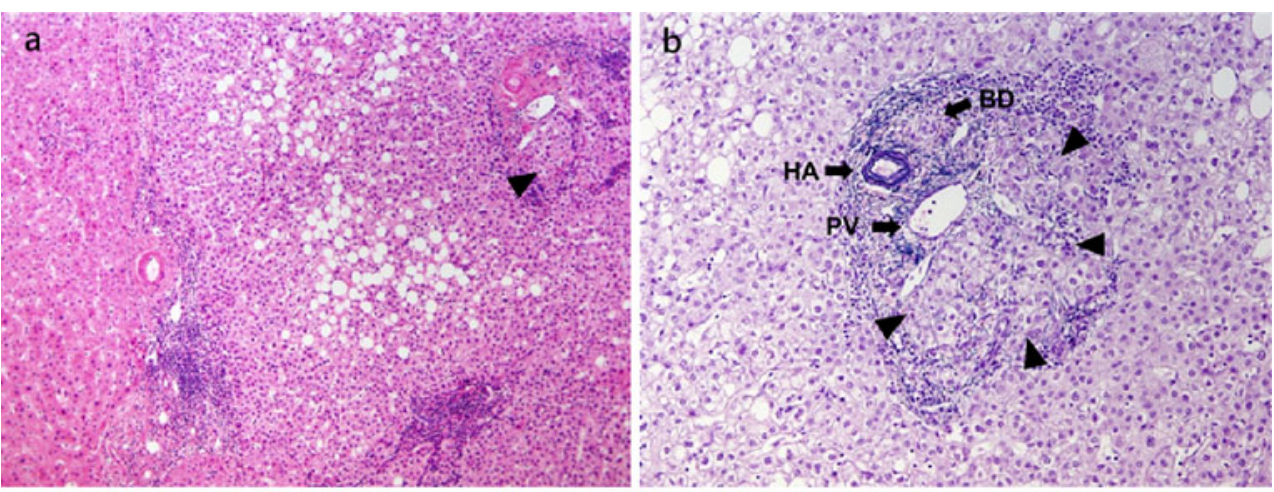

c

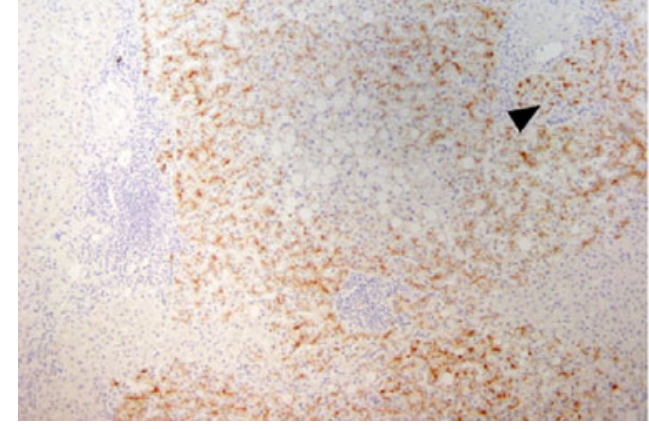

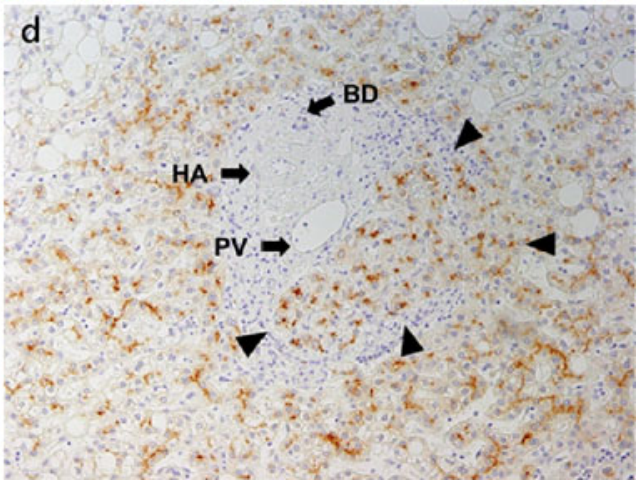

peri-canalicular) was classified as positive when at more than $10 \%$ of the tumorous population. Patients with multiple early $\mathrm{HCC}$ were counted as positive when one of the nodules expressed GPC3. Staining for AFP was classified as positive when at more than $6 \%$ of the tumorous population [17].

\section{Statistical analysis}

Statistical analysis was performed using SAS software (version 9.1.3; SAS Institute, Inc., Cary, NC). Categorical variables were determined using the Chi squared test as appropriate. Continuous variables were expressed as the mean \pm standard deviation and were determined using the student $t$ test. Both disease-free survival (DFS) and overall survival (OS) rates were estimated using the Kaplan-Meier method and differences in survival rate were compared using the log-rank test or Wilcoxon test. Significant variables from the univariate analysis were entered in the multivariate analysis, which was performed using the Cox multivariate proportional hazards model with forward stepwise selection. The $P$ values of $<0.05$ were taken to indicate statistical significance.

\section{Results}

GPC3 expression in patients with early HCC

Among 55 patients, GPC3 expression was positive in 28 (50.9\%) (44 of 99 nodules, $44.4 \%)$ and negative in the remaining $27(49.1 \%$ ) (55 of 99 nodules, $55.6 \%$ ). The surrounding non-cancerous parenchyma stained negative for GPC3 (Fig. 1c). The GPC3-positive cancer cells could be seen invading the interstitial space of residual portal tracts in the cancerous area (Fig. 1d).

Of the 28 patients with GPC3-positive expression, 12 had solitary early HCCs and 16 had multiple early HCCs. With regard to the immunohistochemistry staining pattern of the 28 patients with positive expression, 4 showed a diffused mix pattern (cytoplasmic and pericanalicular) (Fig. 2a, b), 4 showed a peri-canalicular pattern (Fig. 2c) and 20 showed a diffused cytoplasmic staining pattern (Fig. 2d).

\section{AFP expression in patients with early HCC}

AFP-negative expression was observed in all 55 patients with 99 nodules.

\section{Correlation between GPC3 expression} and clinicopathological variables in patients with early HCC

GPC3-positive early HCCs were more frequent than GPC3-negative early HCCs in patients with HCV infection $(P=0.0019)$ and in patients with multiple early HCC $(P<0.0001)$. There was no significant correlation between GPC3 expression and liver cirrhosis, Child-Pugh grade, ICGR $_{15}$, AFP level, PIVKA-II level, operation procedures and tumor size (Table 1). 
Fig. 2 GPC3 immunostaining patterns: a, b Mixed type (cytoplasmic and pericanalicular $)(\times 20)$. c Pericanalicular type (arrow heads) $(\times 40)$. d Cytoplasmic type (arrows) $(\times 40)$
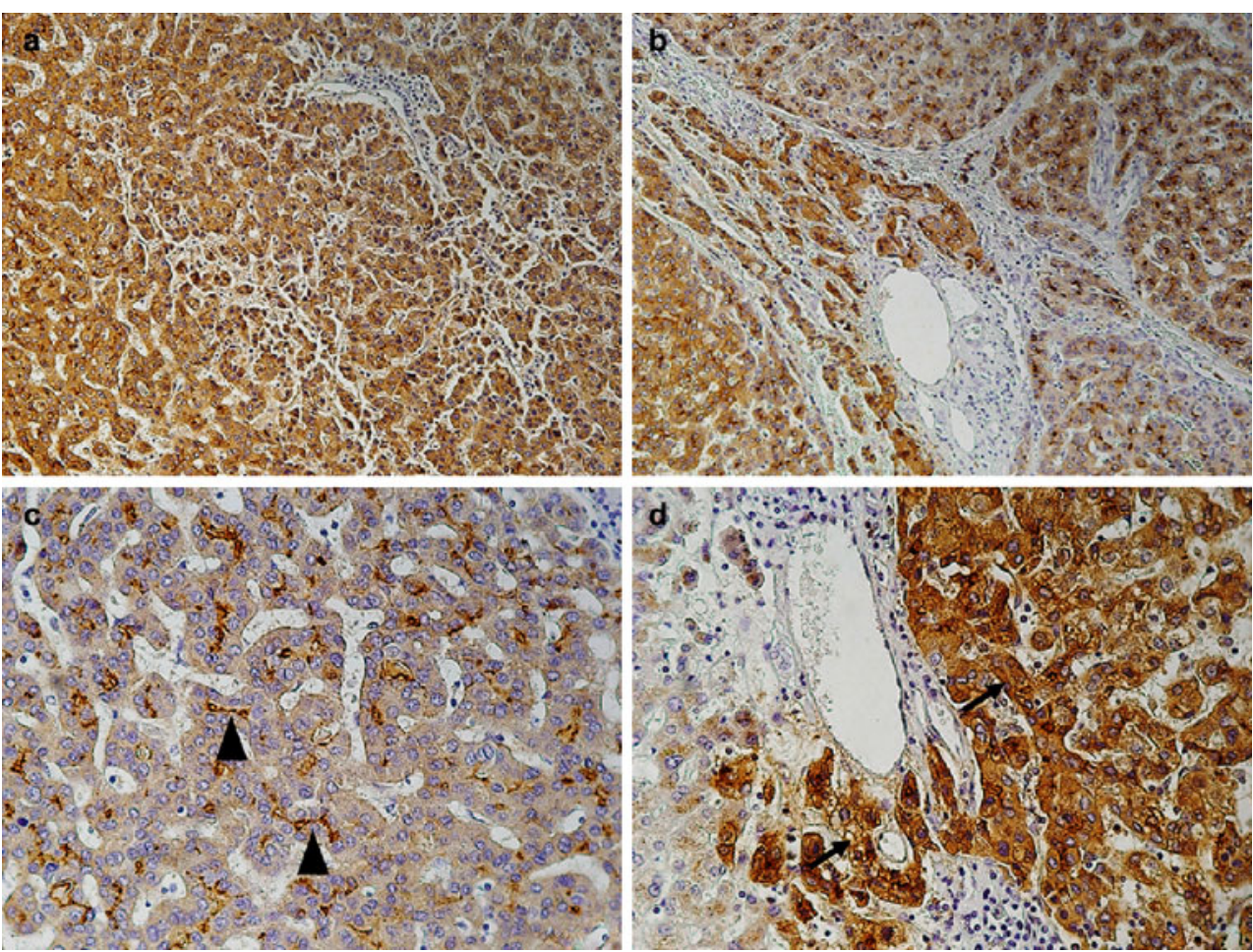

Prognostic significance of GPC3 expression

Univariate analysis revealed that $\mathrm{HBV}$-negative $(P=$ $0.0176)$, HCV-positive $(P=0.0053)$, GPC3 expression $(P=0.0036)$, patients with multiple early $\operatorname{HCC}(P=$ $0.0003)$ and PIVKA-II $\geq 20 \mathrm{mAU} / \mathrm{ml}(P=0.0385)$ were significantly associated with a high risk of recurrence after hepatectomy. Multivariate analysis indicated that HCV infection (risk ratio, 5.126; $95 \%$ CI: 1.461-17.990; $P=0.0107$ ), GPC3 expression (risk ratio, 2.606; $95 \% \mathrm{CI}$ : $1.170-5.802 ; P=0.0190$ ) and multiple early HCC (risk ratio, $2.785 ; 95 \% \mathrm{CI}$ : 1.172-6.619; $P=0.0204)$ were independent prognostic factors for DFS after hepatectomy (Table 2). When survival analysis was performed, GPC3positive early HCCs (5-year DFS rate $27 \%$ ) showed decreased DFS compared with GPC3-negative early HCCs (5-year DFS rate $62 \%)(P=0.0036)$ (Table 2; Fig. 3).

For OS, both univariate and multivariate analyses revealed that PIVKA-II $\geq 20 \mathrm{mAU} / \mathrm{ml}$ and presence of recurrence were significant prognostic factors after hepatectomy. The GPC3 expression, however, showed no significant difference in OS (Table 3).

Recurrence pattern in patients with early HCC

Among 55 patients with early HCC, 33 patients (43 nodules) had recurrence in the remnant liver after hepatectomy. Of those, 27 patients with 34 nodules underwent radiofrequency ablation (RFA) as all 34 nodules showed low density in the arterial phase CT scan with mean tumor size $1.4 \pm 0.1 \mathrm{~cm}$. As for the remaining 6 patients, 3 patients with 3 nodules underwent transcatheter arterial chemoembolization (TACE) and 3 patients with 6 nodules underwent second hepatic resection as those nodules showed high density on the arterial phase CT scan with a mean tumor size $2.4 \pm 0.2 \mathrm{~cm}$. In the 3 patients with 6 nodules who underwent second hepatic resection, the GPC3 expression was positive in all nodules.

\section{Discussion}

Recently, GPC3 has been reported to be a new prognostic factor after curative hepatectomy in patients with HCC, and the expression of GPC3 was also found to be associated with postoperative metastasis in HCC patients [12-14]. There have been a few previous reports of the expression of GPC3 in early HCC [18, 19]. Di Tommaso et al. [18] reported that 11 of 17 patients with early HCC $(64.7 \%)$ showed positive GPC3 expression. However, there have been no previous reports of outcomes after hepatectomy or clinical features in relation to GPC3 expression in patients with early HCC. In our study, GPC3 expression was found in $28(50.9 \%)$ of 55 early HCC patients, and GPC3-positive expression was significantly more frequent in patients with $\mathrm{HCV}$ and multiple early 
Table 2 Prognostic factors for disease free survival (DFS) by univariate and multivariate analysis in patients with early $\mathrm{HCC}$ HBs antigen hepatitis B surface, $H C V$ hepatitis $\mathrm{C}$ virus, $G P C 3$ Glypican3, $I C G R_{15}$ indocyanine green retention rate at $15 \mathrm{~min}$, AFP alpha-fetoprotein, PIVKAII protein induced by vitamin $\mathrm{K}$ absence and antagonist-II, $95 \%$ CI $95 \%$ confidence interval
HCC hepatocellular carcinoma,

\begin{tabular}{|c|c|c|c|c|c|c|c|}
\hline \multirow[t]{2}{*}{ Variables } & \multirow[t]{2}{*}{ Number } & \multicolumn{3}{|c|}{ Univariate analysis } & \multicolumn{3}{|c|}{ Multivariate analysis } \\
\hline & & 1-year 3-year & 5-year & $P$ value & $\begin{array}{l}\text { Relative } \\
\text { risk }\end{array}$ & $95 \% \mathrm{CI}$ & $P$ value \\
\hline
\end{tabular}

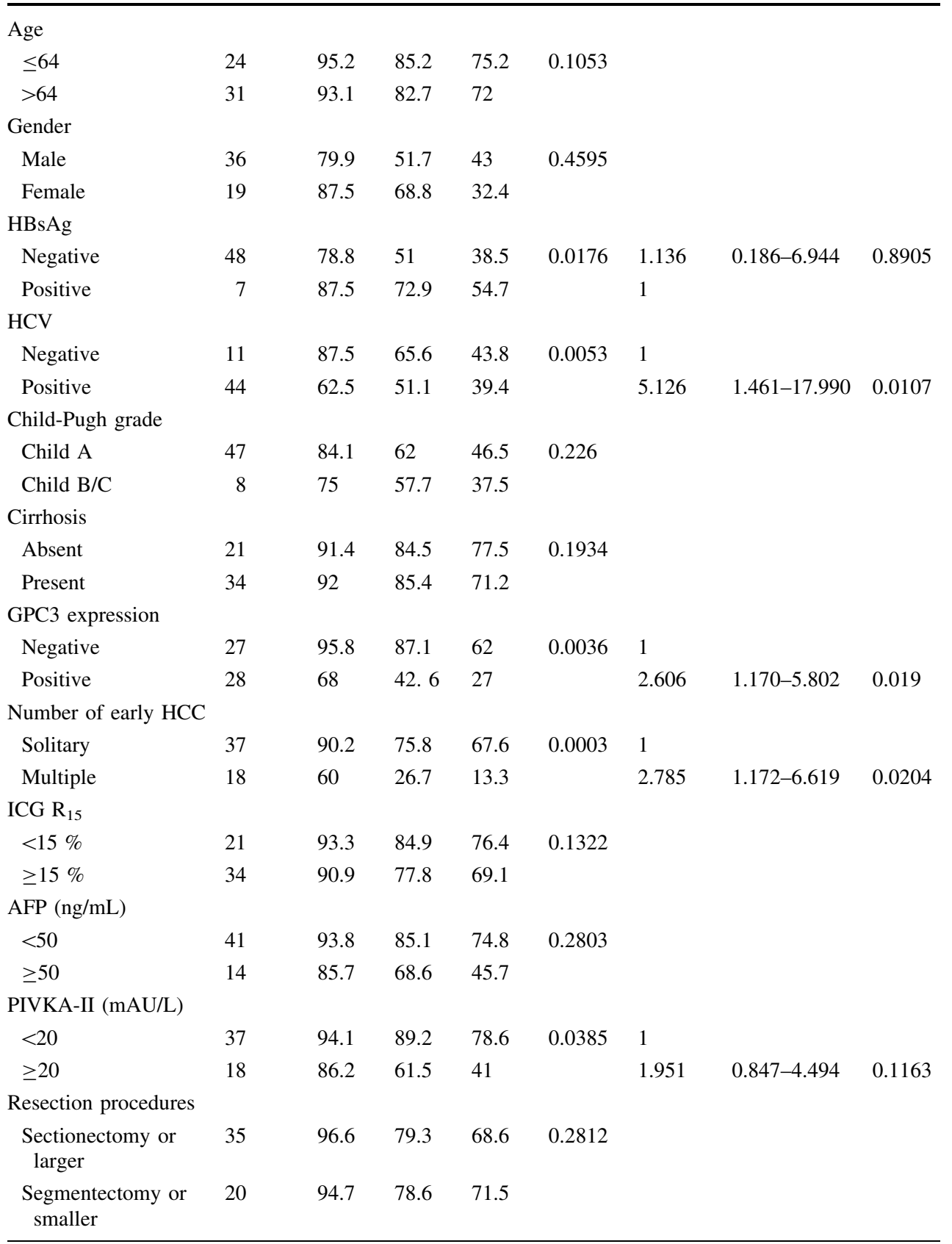

HCC. Furthermore, GPC3-positive early HCC was an independent significant prognostic factor for poor DFS in patients with early HCC.

Early HCC is characterized as pre-invasive or early invasive cancer with a mild deviation of the clinicopathological features from chronic liver disease. The pathological definition of early HCC has been reported by the Liver Cancer Study Group of Japan [15]. However, differential diagnosis of early HCC and dysplastic nodules is sometimes difficult on the basis of pathological findings. The GPC3 is a useful immunohistochemical marker for distinguishing early HCC and small hepatic nodules such as dysplastic nodules, since GPC3 was found to express in early HCC but not in small hepatic nodules $[10,20]$. In addition, Sakamoto et al., reported that a combination of the three-marker panel consisting of GPC3, glutamine synthetase (GS) and heat shock protein 70 (HSP70) can raise the accuracy of distinguishing between dysplastic 


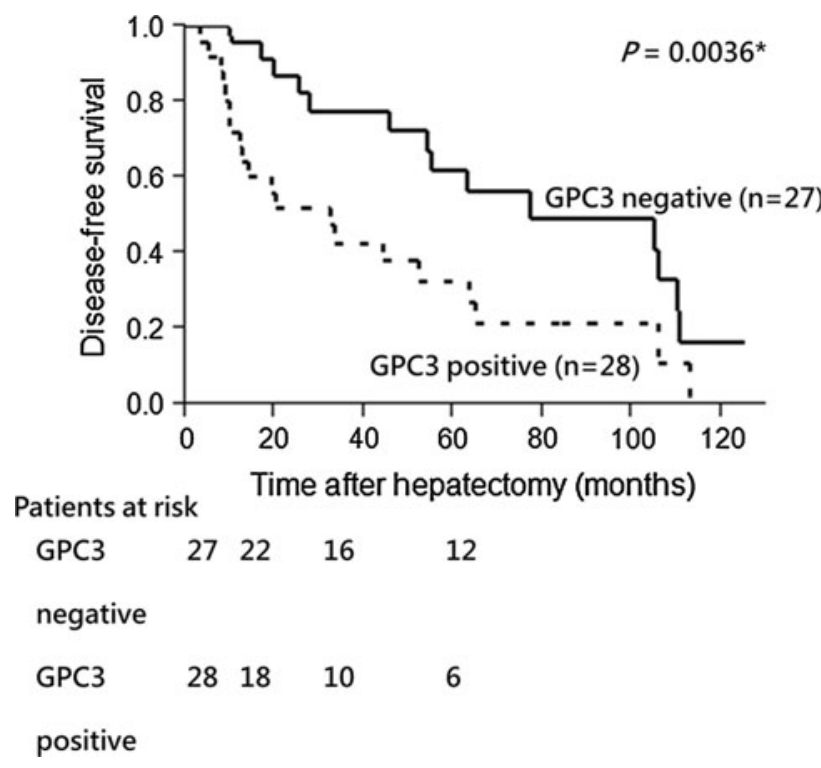

Fig. 3 DFS vs GPC3 expression: Decreasing disease-free survival in GPC3-positive early HCC patients

nodules (DN) and early HCC [21-23]. Therefore, GPC3 is not only a useful marker for differential diagnosis, but also an indication for treatment of early HCC since GPC3positive patients have a high recurrence rate after hepatectomy.

It is well known that AFP is produced in advanced HCC. Both AFP and GPC 3 are oncofetal genes; common factors may regulate their expressions in similar patterns [24]. However, Fujioka et al., reported that AFP expression was not found in 15 well-differentiated HCCs (early HCC) [17]. In the present study, AFP expression was observed to be negative in all 55 patients. Therefore, GPC3 is a useful marker for the diagnosis of early HCC.

Clinically, patients with early HCC have favorable surgical outcomes with better survival rate after hepatectomy $[25,26]$. However, intrahepatic recurrence due to secondary primary $\mathrm{HCC}$ is often seen even in patients with early HCC [27, 28]. Takayama et al. [25] reported that the 5 -year recurrence-free rate was $53 \%$ in patients with early HCC. However, the report did not evaluate prognostic factors for DFS. In the present study, HCV infection, multiple early HCC and GPC3-positive expression were significant independent prognostic factors for DFS in patients with early HCC. The GPC3 expression was observed more frequently in patients with $\mathrm{HCV}$ infection and with multiple early HCCs. Therefore, early HCC patients with GPC3-positive expression should be followed-up after hepatectomy because they have a higher recurrence rate due to secondary primary HCC.

Intrahepatic metastasis and multicentric occurrence of HCC have been known as recurrence patterns of HCC. Intrahepatic metastasis of $\mathrm{HCC}$ is caused by various degrees of vascular invasion in advanced HCC. However, multicentric recurrence of $\mathrm{HCC}$ is caused by secondary primary cancer due to chronic hepatitis or cirrhosis. In our study, 33 of 55 patients with early $\mathrm{HCC}$ recurred due to multicentric occurrence because no vascular invasion of $\mathrm{HCC}$ was seen in all of the patients.

Prolonged active chronic inflammation and extensive fibrosis due to $\mathrm{HCV}$ are responsible for the development of multiple occurrence of HCC [29]. Highly GPC3 expression rate has also been reported in HCV-related HCC patients [30]. In our study, the presence of GPC3 expression was observed more frequently in early HCC patients with HCV infection and those with multiple tumors. Patients with these characteristics tended to result in higher carcinogenesis of early HCC. Highly incidence of recurrence in GPC3 positive early HCC was also observed. These were attributed to the hepatocarcinogenesis in HCV-related patients depending on a persistent active inflammation then followed thereafter by cirrhosis. Such persistent active inflammation may cause continuous necrosis and regeneration of hepatocytes [31]. The GPC3 expression on the cell membrane of proliferate hepatocyte promotes the growth of HCC by stimulating the canonical Wnt pathway during malignant transformation [32] that may be a crucial mechanism to accelerate cancer occurrence in the remnant liver.

Recently, the expression of GPC 3 has been evaluated as a potential candidate for cancer immunotherapy in patients with advanced HCC. Therapeutic implications of GPC3derived peptide vaccination have been demonstrated to be well tolerated and to improve overall survival in patients with advanced HCC [33, 34]. Thus, GPC3-derived peptide vaccination may be required as an adjuvant treatment because 28 of 55 patients (50.9\%) were GPC3-positive and there was a high recurrence rate in such GPC3-positive early HCCs. Therefore, further study with GPC3-derived peptide vaccination to prevent recurrence after treatment for patients with early HCC is required.

Early cancer cells show heterogeneous proliferation on pathological findings. Recently, genetic differences between early $\mathrm{HCC}$ and very early $\mathrm{HCC}$ have been reported [35]. In our present study, GPC3 expression was not positive for homogeneity, but positive for heterogeneity. However, when the GPC3-positive cells accounted for at least $10 \%$ of cancer cells, the rate of multiple early HCC and the recurrence rate after hepatectomy were high. Therefore, GPC3-positive early HCC cells may spread even if the pathological characteristics indicate early HCC.

Vascular invasion and intrahepatic metastasis of HCC are the well-known characteristics and prognostic factors after curative hepatectomy in HCC patients. However, there are no previous reports of prognostic factors of patients with early HCC. In our present study, DFS of 
Table 3 Prognostic factors for overall survival (OS) by univariate and multivariate analysis in patients with early $\mathrm{HCC}$
HCC hepatocellular carcinoma, $H B$ s antigen hepatitis B surface, $H C V$ hepatitis $\mathrm{C}$ virus, GPC3 Glypican3, $I C G R_{15}$ indocyanine green retention rate at $15 \mathrm{~min}$, AFP alpha-fetoprotein, PIVKAII protein induced by vitamin $\mathrm{K}$ absence and antagonist-II, $95 \%$ CI $95 \%$ confidence interval

\begin{tabular}{|c|c|c|c|c|c|c|}
\hline \multirow[t]{2}{*}{ Variables } & \multirow[t]{2}{*}{ Number } & \multicolumn{2}{|c|}{ Univariate analysis } & \multicolumn{3}{|c|}{ Multivariate analysis } \\
\hline & & 5 -year 10 -year & $P$ value & $\begin{array}{l}\text { Relative } \\
\text { risk }\end{array}$ & $95 \% \mathrm{CI}$ & $P$ value \\
\hline
\end{tabular}

\begin{tabular}{|c|c|c|c|c|c|c|c|}
\hline \multicolumn{8}{|l|}{ Age } \\
\hline$\leq 64$ & 24 & 76.4 & 30.3 & \multicolumn{4}{|l|}{0.5204} \\
\hline$>64$ & 31 & 70.5 & 35.2 & & & & \\
\hline \multicolumn{8}{|l|}{ Gender } \\
\hline Male & 36 & 67.2 & 19.2 & \multicolumn{4}{|l|}{0.8057} \\
\hline Female & 19 & 76 & 20.7 & & & & \\
\hline \multicolumn{8}{|l|}{ HBsAg status } \\
\hline Negative & 48 & 75 & 56.3 & \multicolumn{4}{|l|}{0.0988} \\
\hline Positive & 7 & 69.5 & 23.8 & & & & \\
\hline \multicolumn{8}{|l|}{ HCV status } \\
\hline Negative & 11 & 75 & 45 & \multicolumn{4}{|l|}{0.2129} \\
\hline Positive & 44 & 72.1 & 21.3 & & & & \\
\hline \multicolumn{8}{|l|}{ Child-Pugh grade } \\
\hline Child A & 47 & 70.7 & 32.9 & \multicolumn{4}{|l|}{0.2557} \\
\hline Child B/C & 8 & 62.5 & 31.3 & & & & \\
\hline \multicolumn{8}{|l|}{ Cirrhosis } \\
\hline Absent & 21 & 74 & 19 & \multicolumn{4}{|l|}{0.1893} \\
\hline Present & 34 & 71.1 & 12.8 & & & & \\
\hline \multicolumn{8}{|l|}{ GPC3 expression } \\
\hline Negative & 27 & 70.2 & 26.9 & \multicolumn{4}{|l|}{0.4435} \\
\hline Positive & 28 & 67.9 & 8.6 & & & & \\
\hline \multicolumn{8}{|l|}{ Number of early HCC } \\
\hline Solitary & 37 & 75.1 & 27.4 & \multicolumn{4}{|l|}{0.1323} \\
\hline Multiple & 18 & 75.6 & 29.6 & & & & \\
\hline \multicolumn{8}{|l|}{ ICG $\mathrm{R}_{15}$} \\
\hline$<15 \%$ & 21 & 75 & 41.3 & \multicolumn{4}{|l|}{0.557} \\
\hline$\geq 15 \%$ & 34 & 74.6 & 26.7 & & & & \\
\hline \multicolumn{8}{|l|}{ AFP (ng/mL) } \\
\hline$<50$ & 41 & 74.9 & 57.8 & \multicolumn{4}{|l|}{0.6866} \\
\hline$\geq 50$ & 14 & 66.7 & 44.4 & & & & \\
\hline \multicolumn{8}{|l|}{ PIVKA-II (mAU/L) } \\
\hline$<20$ & 37 & 76.9 & 33 & \multirow[t]{2}{*}{0.0401} & 1 & & \\
\hline$\geq 20$ & 18 & 50.4 & 16.8 & & 2.32 & $1.003-5.370$ & 0.0493 \\
\hline \multicolumn{8}{|l|}{ Recurrent } \\
\hline Absent & 22 & 84.2 & 65.5 & \multirow[t]{2}{*}{0.0006} & 1 & & \\
\hline Present & 33 & 45.9 & 22.9 & & 3.708 & $1.800-7.868$ & 0.0004 \\
\hline \multicolumn{8}{|l|}{ Resection procedures } \\
\hline Sectionectomy or larger & 35 & 63.1 & 17.8 & \multicolumn{4}{|l|}{0.3079} \\
\hline Segmentectomy or smaller & 20 & 77.9 & 22.3 & & & & \\
\hline
\end{tabular}

GPC3-positive early HCC patients was significantly worse than that of GPC3-negative early HCC patients. However, OS of GPC3-positive early HCC patients showed no significant difference than GPC3-negative patients. Because hepatic recurrences were mostly found small and early HCCs from image detection, appropriate treatments for them had been immediately performed. In conclusion,
GPC3 participate in the early stage of hepatocarcinogenesis and are capable of being a new prognostic factor for DFS in patients with early HCC.

Acknowledgments This work was supported by the Global COE program, Multidisciplinary Education and Research Center for Regenerative Medicine (MERCREM), from the Ministry of Education, Culture, Sports Science, and Technology (MEXT), Japan. The 
authors are also indebted to Satoru Shimizu, Ph.D., from the Medical Research Institute of Tokyo Women's Medical University for statistical expertise and Associate Professor Raoul Breugelmans from the Department of Medical Education of Tokyo Medical University for his review of this manuscript.

Conflict of interest The authors declare that they have no conflict of interest.

Open Access This article is distributed under the terms of the Creative Commons Attribution Noncommercial License which permits any noncommercial use, distribution, and reproduction in any medium, provided the original author(s) and the source are credited. The exclusive right to any commercial use of the article is with Springer.

\section{References}

1. Sherman M. Hepatocellular carcinoma: epidemiology, surveillance, and diagnosis. Semin Liver Dis. 2010;30:3-16.

2. Filmus J, Capurro M, Rast J. Glypicans. Genome Biol. 2008; 9:224.

3. Aviel-Ronen S, Lau SK, Pintilie M, Lau D, Liu N, Tsao MS, et al. Glypican-3 is overexpressed in lung squamous cell carcinoma, but not in adenocarcinoma. Mod Pathol. 2008;21:817-25.

4. Thway K, Selfe J, Missiaglia E, Fisher C, Shipley J. Glypican-3 is expressed in rhabdomyosarcomas but not adult spindle cell and pleomorphic sarcomas. J Clin Pathol. 2011;64:587-91.

5. Kandil D, Leiman G, Allegretta M, Evans M. Glypican-3 protein expression in primary and metastatic melanoma: a combined immunohistochemistry and immunocytochemistry study. Cancer. 2009;117:271-8.

6. Nakatsura T, Nishimura Y. Usefulness of the novel oncofetal antigen glypican-3 for diagnosis of hepatocellular carcinoma and melanoma. BioDrugs. 2005;19:71-7.

7. Iglesias BV, Centeno G, Pascuccelli H, Ward F, Peters MG, Filmus J, et al. Expression pattern of glypican-3 (GPC3) during human embryonic and fetal development. Histol Histopathol. 2008;23:1333-40.

8. Llovet JM, Chen Y, Wurmbach E, Roayaie S, Fiel MI, Schwartz $\mathrm{M}$, et al. A molecular signature to discriminate dysplastic nodules from early hepatocellular carcinoma in HCV cirrhosis. Gastroenterology. 2006;131:1758-67.

9. Wang XY, Degos F, Dubois S, Tessiore S, Allegretta M, Guttmann RD, et al. Glypican-3 expression in hepatocellular tumors: diagnostic value for preneoplastic lesions and hepatocellular carcinomas. Hum Pathol. 2006;37:1435-41.

10. Coston WM, Loera S, Lau SK, Ishizawa S, Jiang Z, Wu CL, et al. Distinction of hepatocellular carcinoma from benign hepatic mimickers using Glypican-3 and CD34 immunohistochemistry. Am J Surg Pathol. 2008;32:433-44.

11. Suzuki M, Sugimoto K, Tanaka J, Tameda M, Inagaki Y, Kusagawa $\mathrm{S}$, et al. Up-regulation of glypican-3 in human hepatocellular carcinoma. Anticancer Res. 2010;30:5055-61.

12. Ning S, Bin C, Na H, Peng S, Yi D, Xiang-hua Y, et al. Glypican3 , a novel prognostic marker of hepatocellular cancer, is related with postoperative metastasis and recurrence in hepatocellular cancer patients. Mol Biol Rep. 2012;39:351-7.

13. Shirakawa H, Suzuki H, Shimomura M, Kojima M, Gotohda N, Takahashi S, et al. Glypican-3 expression is correlated with poor prognosis in hepatocellular carcinoma. Cancer Sci. 2009;100: 1403-7.
14. Yu MC, Lee YS, Lin SE, Wu HY, Chen TC, Lee WC, et al. Recurrence and poor prognosis following resection of small hepatitis B-related hepatocellular carcinoma lesions are associated with aberrant tumor expression profiles of glypican 3 and osteopontin. Ann Surg Oncol. 2012;3:S455-63.

15. General rules for the clinical and pathological study of primary liver cancer. Liver cancer study group of Japan. Classification of primary liver cancer. 2nd ed. Tokyo: Kanehara and Co. 2003. p 34-8.

16. Pathologic diagnosis of early hepatocellular carcinoma: a report of the international consensus group for hepatocellular neoplasia. Hepatology. 2009;49:658-64.

17. Fujioka M, Nakashima Y, Nakashima O, Kojiro M. Immunohistologic study on the expressions of alpha-fetoprotein and protein induced by vitamin $\mathrm{K}$ absence or antagonist II in surgically resected small hepatocellular carcinoma. Hepatology. 2001;34:1128-34.

18. Di Tommaso L, Destro A, Seok JY, Balladore E, Terracciano L, Sangiovanni A, et al. The application of markers (HSP70 GPC3 and GS) in liver biopsies is useful for detection of hepatocellular carcinoma. J Hepatol. 2009;50:746-54.

19. Capurro M, Wanless IR, Sherman M, Deboer G, Shi W, Miyoshi E, et al. Glypican-3: a novel serum and histochemical marker for hepatocellular carcinoma. Gastroenterology. 2003;125:89-97.

20. Di Tommaso L, Destro A, Fabbris V, Spagnuolo G, Laura Fracanzani A, Fargion S, et al. Diagnostic accuracy of clathrin heavy chain staining in a marker panel for the diagnosis of small hepatocellular carcinoma. Hepatology. 2011;53:1549-57.

21. Libbrecht L, Severi T, Cassiman D, Vander Borght S, Pirenne J, Nevens F, et al. Glypican-3 expression distinguishes small hepatocellular carcinomas from cirrhosis, dysplastic nodules, and focal nodular hyperplasia-like nodules. Am J Surg Pathol. 2006;30:1405-11.

22. Di Tommaso L, Franchi G, Park YN, Fiamengo B, Destro A, Morenghi E, et al. Diagnostic value of HSP70, glypican 3, and glutamine synthetase in hepatocellular nodules in cirrhosis. Hepatology. 2007;45:725-34.

23. Sakamoto M, Effendi K, Masugi Y. Molecular diagnosis of multistage hepatocarcinogenesis. Jpn J Clin Oncol. 2010;40: 891-6.

24. Morford LA, Davis C, Jin L, Dobierzewska A, Peterson ML, Spear BT. The oncofetal gene glypican 3 is regulated in the postnatal liver by zinc fingers and homeoboxes 2 and in the regenerating liver by alpha-fetoprotein regulator 2. Hepatology. 2007;46:1541-7.

25. Takayama T, Makuuchi M, Hirohashi S, Sakamoto M, Yamamoto J, Shimada K, et al. Early hepatocellular carcinoma as an entity with a high rate of surgical cure. Hepatology. 1998;28: 1241-6.

26. Yamamoto M, Takasaki K, Otsubo T, Katsuragawa H, Katagiri S, Yoshitoshi K, et al. Favorable surgical outcomes in patients with early hepatocellular carcinoma. Ann Surg. 2004;239:395-9.

27. Llovet JM, Burroughs A, Bruix J. Hepatocellular carcinoma. Lancet. 2003;362:1907-17.

28. Inoue K, Takayama T, Higaki T, Watanabe Y, Makuuchi M. Clinical significance of early hepatocellular carcinoma. Liver Transpl. 2004;10:S16-9.

29. Utsunomiya I. Pathological study on multicentric occurrence of hepatocellular carcinoma. Kurume Med J. 2005;52:133-8.

30. Yorita K, Takahashi N, Takai H, Kato A, Suzuki M, Ishiguro T, et al. Prognostic significance of circumferential cell surface immunoreactivity of glypican-3 in hepatocellular carcinoma. Liver Int. 2011;31:120-31.

31. Bartosch B, Thimme R, Blum HE, Zoulim F. Hepatitis C virusinduced hepatocarcinogenesis. J Hepatol. 2009;51:810-20. 
32. Capurro MI, Xiang YY, Lobe C, Filmus J. Glypican-3 promotes the growth of hepatocellular carcinoma by stimulating canonical Wnt signaling. Cancer Res. 2005;65:6245-54.

33. Ishiguro T, Sugimoto M, Kinoshita Y, Miyazaki Y, Nakano K, Tsunoda $\mathrm{H}$, et al. Anti-glypican 3 antibody as a potential antitumor agent for human liver cancer. Cancer Res. 2008;68: 9832-8.

34. Sawada Y, Yoshikawa T, Nobuoka D, Shirakawa H, Kuronuma $\mathrm{T}$, Motomura Y, et al. Phase I trial of a glypican-3-derived peptide vaccine for advanced hepatocellular carcinoma: immunologic evidence and potential for improving overall survival. Clin Cancer Res. 2012;18:3686-96.

35. Hoshida Y, Villanueva A, Kobayashi M, Peix J, Chiang DY, Camargo A, et al. Gene expression in fixed tissues and outcome in hepatocellular carcinoma. N Engl J Med. 2008;359: 1995-2004. 